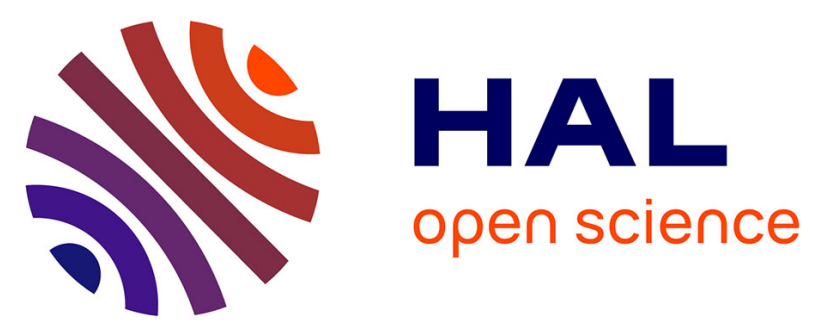

\title{
Factors associated with perceived loss of libido in people who inject opioids: Results from a community-based survey in France
}

\author{
Laélia Briand Madrid, Stéphane Morel, Khadim Ndiaye, Salim Mezaache, \\ Daniela Rojas Castro, Marion Mora, Fabrice Olivet, Virginie Laporte, \\ Camelia Protopopescu, Patrizia Carrieri, et al.
}

\section{To cite this version:}

Laélia Briand Madrid, Stéphane Morel, Khadim Ndiaye, Salim Mezaache, Daniela Rojas Castro, et al.. Factors associated with perceived loss of libido in people who inject opioids: Results from a community-based survey in France. Drug and Alcohol Dependence, 2018, 190, pp.121-127. 10.1016/j.drugalcdep.2018.05.030 . hal-01873283

\section{HAL Id: hal-01873283 \\ https://hal.science/hal-01873283}

Submitted on 18 Feb 2019

HAL is a multi-disciplinary open access archive for the deposit and dissemination of scientific research documents, whether they are published or not. The documents may come from teaching and research institutions in France or abroad, or from public or private research centers.
L'archive ouverte pluridisciplinaire HAL, est destinée au dépôt et à la diffusion de documents scientifiques de niveau recherche, publiés ou non, émanant des établissements d'enseignement et de recherche français ou étrangers, des laboratoires publics ou privés. 
Publié dans Drug and Alcohol Dependance le 1er Septembre 2018, volume 190, pages 121-127

Factors associated with perceived loss of libido in people who inject opioids: results from a community-based survey in France.

BRIAND MADRID Laélia ${ }^{1,2}$, MOREL Stéphane ${ }^{3}$, NDIAYE Khadim ${ }^{1,2}$, MEZAACHE Salim $^{1,2}$, ROJAS CASTRO Daniela ${ }^{1,3,4,5}$, MORA Marion ${ }^{1,2}$, OLIVET Fabrice ${ }^{6}$, LAPORTE Virginie $^{3}$, PROTOPOPESCU Camelia ${ }^{1,2}$, CARRIERI Patrizia ${ }^{1,2}$, ROUX Perrine $^{1,2}$

${ }^{1}$ Aix Marseille Univ, INSERM, IRD, SESSTIM, Sciences Economiques \& Sociales de la Santé \& Traitement de l'Information Médicale, Faculté de médecine, 27 boulevard Jean Moulin, 13385 Marseille, France.

${ }^{2}$ ORS PACA, Observatoire régional de la santé Provence-Alpes-Côte d'Azur, Faculté de médecine, 27 boulevard Jean Moulin, 13385 Marseille, France.

${ }^{3}$ AIDES, 14 rue Scandicci, 93508 Pantin, France.

${ }^{4}$ Groupe de Recherche en Psychologie Sociale (EA 4163), Université Lyon 2, 5 avenue Pierre Mendès France, 69676 Bron, France.

${ }^{5}$ Coalition plus, 14 rue Scandicci, 93508 Pantin, France.

${ }^{6}$ ASUD, 32 rue Vitruve, 75020 Paris, France.

Corresponding author: Briand Madrid Laélia, SESSTIM - INSERM U912 - ORS PACA, IHU Infection Méditerranée, 19-21 boulevard Jean Moulin, 13005 Marseille. France. Tel: +33413732277@: laelia.briand-madrid@inserm.fr 


\begin{abstract}
Background: Regular consumption of opioids exposes individuals to several side effects. One of these is loss of libido, which has a negative impact on quality of life. We used a crosssectional community-based survey of people who inject opioids to study factors associated with loss of libido, and more particularly the impact of the type of opioid injected.
\end{abstract}

Methods: This secondary study was conducted throughout France in 2015 and involved 514 people who inject opioids that completed questionnaires including a specific question about libido. Self-reported sociodemographic characteristics, drug consumption and injection-related data were collected using a brief questionnaire administered either through face-to-face interviews (in low-threshold and addiction care services) or online (on a French drug-use selfhelp website). Two different models were used to identify factors associated with loss of libido: a simple logistic regression and a two-step Heckman model.

Results: Forty-three percent of the participants reported loss of libido. The first model showed that the following factors were strongly associated with loss of libido: filling in the questionnaire online $(\mathrm{OR}[95 \% \mathrm{CI}]=2.55[1.64 ; 3.96] ; \mathrm{p}<0.001)$, reporting that morphine sulfate $(\mathrm{OR}[95 \% \mathrm{CI}]=2.67[1.56 ; 4.58] ; \quad \mathrm{p}<0.001) \quad$ or $\quad$ methadone $\quad(\mathrm{OR}[95 \% \mathrm{CI}]=2.50[1.13 ; 5.56]$; $\mathrm{p}=0.030$ ) was the opioid they injected most (versus buprenorphine), and reporting benzodiazepine use $(\mathrm{OR}[95 \% \mathrm{CI}]=1.62[1.07 ; 2.44] ; \mathrm{p}=0.033)$. In the two-step Heckman model which corrected for selection bias, along with these factors, reporting heroin as the opioid injected most was also strongly associated.

Conclusion: Our findings showed that full-opioid agonists can have a negative impact on libido when injected regularly. Libido can improve quality of life and should be routinely discussed through counselling in prevention services with people who inject drugs. 
Key words: opioid agonist treatment, opioid use, sexual dysfunction, web self-administration surveys, sensitive questions.

\section{Highlights}

- Loss of libido is a well-known side effect of opioid use but is still a taboo subject. No study to date has investigated in detail the impact of the type of opioids injected and other correlates on libido.

- In this community-based survey, participants who answered the questionnaire online were more likely to report loss of libido than those who answered it in face-to-face interviews.

- The type of opioid consumed plays a significant role in how serious the loss of libido is. Buprenorphine appears to be the opioid with the weakest effect.

\subsection{Introduction}

Opioid substitution treatments (OST), specifically methadone and buprenorphine, were introduced in France in the early 1990s. They provide several health benefits for opioid users, especially a reduction in fatal overdoses and HIV transmission (Emmanuelli and Desenclos, 2005), an improvement in the management of HIV (Cadet-Taïrou et al., 2015; Roux et al., 2009), better global health, and social improvements like reduced criminal activity and increased employment rates (Blom Nilsson et al., 2015; Hubbard et al., 2003; Lawrinson et al., 2008). The number of persons prescribed OST in France in 2014 was estimated at 180000 (Brisacier, 2017). 
Buprenorphine is the most prescribed OST in France, mainly because it can be initiated through primary care physicians, whereas methadone is restricted to addiction services in hospitals and addiction centers (Carrieri et al., 2014). Morphine sulfate, commonly prescribed as an analgesic for persistent pain, can also be prescribed in exceptional circumstances as an OST, in case of intolerance to or inefficacy of methadone or buprenorphine. However, it is not an approved treatment for opioid dependence in France (Brisacier, 2017).

One well-known side effect of opioid use is sexual dysfunction (Cicero et al., 1975; Santen et al., 1975). The effects of opioids on sexuality have been known since antiquity: consumed occasionally and at low doses, they can boost both desire and sexual performance (Hernández and Alfonso, 1997). At higher doses and taken regularly, the opposite is true, although not systematically (Chekuri et al., 2012; El-Bassel et al., 2003). For men, studies in the 1970s posited that heroin has a greater negative impact than methadone on retarded ejaculation and impotence (Mintz et al., 1974), but that the quality of sperm and testosterone levels are lower in those taking methadone (Cicero et al., 1975). Another study found that one month of heroin abstinence is necessary to recover normal testosterone levels (Mendelson and Mello, 1975). For women in the same decade, only one published study explored heroin and methadone effects on menstruation and showed abnormal symptoms for both opioids in half of those studied (Santen et al., 1975). More recent studies have also shown the lower impact of methadone on sexual dysfunction than heroin. In men, sexual dysfunction can even be reduced after methadone treatment initiation (Babakhanian et al., 2012; Zhang et al., 2014), with the exception of premature ejaculation (Chekuri et al., 2012). To date, only four studies on sexual dysfunction have focused on buprenorphine - perhaps because buprenorphine is available in fewer countries than methadone - and only one of these included women. Their results indicated that buprenorphine use is associated with less sexual dysfunction than methadone or heroin (AlGommer et al., 2007; Bliesener et al., 2005; Giacomuzzi et al., 2009; Yee et al., 2016). For both 
buprenorphine and methadone, the dosage action threshold and duration of treatment are still unknown, as are the levels of testosterone for men.

In order to boost libido, OST intake must be reduced but this has direct consequences on adherence to treatment, and may lead to withdrawal symptoms and craving. Furthermore, individuals may use other drugs to compensate for loss of libido (Chekuri et al., 2012; Xia et al., 2013). Loss of libido impacts quality of life, especially mental health (Dunn et al., 1999; Rosen and Althof, 2008). In sexual relations between steady partners and between occasional partners, reduced libido can lead to conflict due to misunderstanding or frustration, and may have a negative impact on sexual intimacy and self-image (Dunn et al., 1999). Studies have shown that the enjoyment of sexuality is associated with improved quality of life (Teoh et al., 2017; Yee et al., 2016). Despite the importance of this side-effect, people on OST who inject drugs are not frequently asked about their sexual life by health professionals and few services exist to deal with sexual health in this population (Chekuri et al., 2012).

Few studies have examined loss of libido in different populations of people who inject opioids (Yee et al., 2014). The present secondary analysis of the community-based survey PrebupIV initially conducted to assess the willingness of people who inject drugs (PWID) frequently to receive a novel intravenous buprenorphine treatment (Roux et al., 2017) - enabled us to explore libido, which is rarely discussed with health professionals or field workers or indeed in the drug user community. Factors associated with loss of libido, and more particularly, the impact of the type of opioid injected, may provide clues to field workers about how to talk about sexuality, and to doctors about which OST to prescribe.

\subsection{Material and methods}

\subsection{Study design}


PrebupIV is a cross-sectional community-based participatory research study performed by the association AIDES and the French national institute for medical research (INSERM) in collaboration with other associations (Fédération Addiction, ASUD, Médecins du Monde). Its aim was to assess acceptability of a novel intravenous buprenorphine treatment (Roux et al., 2017). It was conducted in France between May and August 2015 in low-threshold addiction centers (free centers which provide various services, including needle exchange programs, where no requirements are needed for attendance), in general practitioner offices, in community-based associations, and through the French drug-use self-help website Psychoactif.org. The community-based nature of PrebupIV meant that PWID and people working with them (professionals and volunteers) were involved in drawing up the survey questionnaire, in terms of the topics to include and the types of questions to ask. The present study is a secondary analysis of data from PrebupIV, which received authorization from the national French Data Protection Authority (CNIL). All procedures performed were in accordance with the 1964 Helsinki declaration and later amendments.

\subsection{Participants}

Participants were recruited from all over France. The study questionnaire was filled in by PWID either online, thanks to a link on the home page of the website Psychoactif.org, or during a faceto-face interview with field workers or physicians who invited them to participate. These two methods were chosen to capture as diverse a population of PWID as possible, including the 'hidden' PWID sub-population who do not come to low-threshold addiction centers but use the internet for drug information (harm reduction, side effects, support, etc.). This sub-population is considered to be more socially integrated (employed, stable housing, etc.). Participants were eligible for this study if 1) they were 18 years or older, 2) were French-speaking, and 3) had injected opioids (heroin, buprenorphine, methadone, morphine sulfate, oxycodone, codeine, fentanyl or tramadol) at least once during the previous week. All participants in the survey 
provided informed consent. No incentives - financial or other - were offered for their participation. A total of 557 PWID completed the questionnaire but those with no data on loss of libido were excluded (N=43) (Figure 1).

\subsection{Questionnaires and variables}

The online and face-to-face questionnaires had the same questions divided into 3 sections: 1) socio-demographic characteristics, behavioral and health data (gender, age, housing, employment, type of OST, HIV/HCV/HBV status, etc.); 2) drug use practices (type, dose, frequency, polydrug use, drug use-related risk practices, etc.), reasons for using drugs by injection, perceived complications (including loss of libido); 3) acceptability of a novel intravenous buprenorphine treatment, associated preferences for the type of injecting system (simple vial with syringe or pre-filled syringe) for this treatment and acceptability of daily IV buprenorphine treatment doses. More details are available in Roux et al., 2017. Loss of libido was one of 14 possible responses to the question related to complications arising from drug injection: "Have you had any of the following complications because of drug injection? (many answers possible)" The type of opioid most consumed could be an OST, prescribed or not, or heroin or another type of opioid (oxycodone, codeine, fentanyl and tramadol).

\subsection{Statistical analyses}

2.4.1. Description of the sample: comparison between participants who completed the questionnaire online and those who completed it face to face

We compared the individual characteristics between participants who completed the questionnaire online and those who completed it face to face using a Chi-square or exact Fisher test for discrete variables, and Student's T test for continuous variables.

\subsubsection{Factors associated with loss of libido}


To study factors associated with loss of libido we used two different models, a simple logistic regression (model 1) and then a two-step Heckman model (model 2) to take into account the potential bias associated with the different types of questioning (i.e., online versus face-to-face)

- Model 1 : logistic regression model

First, we studied factors associated with loss of libido using a logistic regression model. We used a threshold P-value $<0.20$ in univariate analyses to identify the variables eligible to enter the multivariable logistic regression model (Budtz-Jørgensen et al., 2007). A backward procedure was then used to select the explanatory variables in the final multivariable model, with a P-value $<0.05$.

\section{- Model 2: A two-step Heckman model}

Second, a two-step Heckman model was used to account for the potential bias arising from the non-random assignment of the participants between the "online questionnaire" and "face-toface questionnaire" groups. In the first step, a probit model was used to identify the factors associated with the type of questioning. In the second step, a probit model was used to identify factors associated with loss of libido. The residuals of the model of the first step were used to compute the inverse Mills ratio (IMR), which was then introduced as a covariate into the model of the second step in order to correct for potential bias due to non-random assignment of the two groups. We used a threshold P-value $<0.20$ in univariate analyses after adjustment for the IRM term, to identify the variables eligible to enter the second-step multivariable Heckman model. Bias-corrected confidence intervals and P-values in the second step were based on 500 bootstrap replicates. A backward procedure was then used to select the explanatory variables for the final multivariable model, with a $\mathrm{P}$-value $<0.05$.

\subsection{Results}




\subsection{Description of the study sample}

A total of 514 participants completed the questionnaires and answered the question about loss of libido (Figure 1). Table 1 shows socio-demographic characteristics and types of substance used. Twenty percent of the study sample were female and median [IQR] age was 34 [28; 41] years. Twenty-nine percent were employed and 56\% had stable housing. The opioid most frequently injected was buprenorphine (54\%), followed by heroin $(20 \%)$, morphine sulfate (17\%) and methadone (6\%). Median injection duration [IQR] was 7 years [3; 11]. Seventy percent were currently prescribed OST (which could have been the opioid most frequently injected). In terms of polydrug use, 59\% also reported stimulant use, 34\% benzodiazepine use and $43 \%$ alcohol use. Forty-three percent of the study sample reported loss of libido.

\subsection{Factors associated with loss of libido}

In univariate analyses, shown in Table 2, we found that the type of opioid most frequently injected had an impact on loss of libido, with buprenorphine being less likely to have an impact than morphine sulfate $(\mathrm{OR}[95 \% \mathrm{CI}]=2.75[1.63 ; 4.65] ; \mathrm{p}<0.001)$, heroin $(\mathrm{OR}[95 \% \mathrm{CI}]=2.05$ $[1.25 ; 3.36] ; \mathrm{p}=0.004)$ and methadone $(\mathrm{OR}[95 \% \mathrm{CI}]=2.36[1.08 ; 5.13] ; \mathrm{p}=0.031)$. No sociodemographic factors were associated with loss of libido. However, participants who filled in the questionnaire online (versus face to face) reported loss of libido more frequently (OR [95\% $\mathrm{CI}]=2.44[1.64 ; 3.64] ; \mathrm{p}<0.001)$. This result led us to conduct a Heckman model to correct for any bias arising from the two different methods used to administer the questionnaire (Table 2). The Heckman model provided the same results, except for methadone $(\mathrm{p}=0.060)$.

After multiple adjustment, all variables remained associated with the outcome in the logistic regression (see Table 3), except for heroin. Participants who injected methadone (OR [95\% $\mathrm{CI}]=2.50[1.13 ; 5.56] ; \mathrm{p}=0.030)$ or morphine sulfate $(\mathrm{OR}[95 \% \mathrm{CI}]=2.67[1.56 ; 4.58]$; $\mathrm{p}<0.001$ ) were approximately 2.5 times more likely to report loss of libido than buprenorphine 
injectors. Those who reported benzodiazepine use were also significantly more likely to report loss of libido (OR $[95 \% \mathrm{CI}]=1.62[1.07 ; 2.44] ; \mathrm{p}=0.022)$. Finally, participants who answered online were 2.5 times more likely to report loss of libido than those who answered it face to face $(\mathrm{OR}[95 \% \mathrm{CI}]=2.55[1.64 ; 3.96] ; \mathrm{p}<0.001)$. After implementing the two-step Heckman model to correct for the heterogeneity in how the questionnaire was administered, only benzodiazepine use no longer remained positively associated with loss of libido, while heroin was associated $(\mathrm{OR}[95 \% \mathrm{CI}=0.42[0.07 ; 0.76] ; \mathrm{p}=0.019)$.

\subsection{Discussion}

The main result of this sub-study of the PrebupIV survey suggests that people who regularly inject full-agonist opioids are more likely to report reduced libido than buprenorphine injectors. To our knowledge, this is the first time that loss of libido has been investigated in people who inject different opioids. More specifically, we found that people who mainly injected heroin or morphine sulfate or methadone (whether prescribed or not) were more than twice as likely to report a loss of libido than buprenorphine users (whether prescribed or not). These findings corroborate the results of other studies showing that methadone and heroin have a greater negative impact on sexual functioning than buprenorphine in both men (Al-Gommer et al., 2007; Hallinan et al., 2009; Quaglio et al., 2008; Yee et al., 2016) and women (Giacomuzzi et al., 2009). The choice to take morphine sulfate instead of other OST may be related to its stronger "high" effect and this may be the reason for the greater loss of libido reported in this population. The PrebupIV survey (Roux et al., 2017) showed that morphine sulfate was used to get high more frequently than methadone and buprenorphine. Another French survey investigating this substance reported that $77.6 \%$ of users were searching for a rewarding effect (Peyriere et al., 2016). 
These findings are relevant in regards to the effects of OST and opioids in general on the brain and hormonal system. Opioid consumption stimulates $\mu$-opioid receptors which inhibit the function of gonadotropin-releasing hormone which lowers the release of sexual hormones, especially testosterone (Cicero et al., 1975; Mendelson and Mello, 1975; Mintz et al., 1974). Although a correlation between opioids and sexual dysfunction has been established, no study has yet found any dose-response relationship between testosterone level and opioid consumption (Gerra et al., 2015; Gulliford, 1998; Zhang et al., 2014). The link between buprenorphine - a partial-opioid agonist - and testosterone levels, has not been clearly established, as many results are contradictory (Bliesener et al., 2005; Gulliford, 1998; Hallinan et al., 2009). However, declarations from participants in various studies would suggest that partial-agonist opioids have less impact on sexual dysfunction than full-agonist opioids like heroin, methadone or morphine sulfate (Al-Gommer et al., 2007; Yee et al., 2014).

Another result from this sub-study is that benzodiazepine users were more likely to report loss of libido. This is in line with a study by La Torre et al., which analyzed the literature on mood stabilizers and anxiolytic drugs, highlighting their negative impact on sexual functioning (La Torre et al., 2014). Anxiety - one of the reasons for prescribing benzodiazepines - is itself a factor of sexual dysfunction (Barlow, 1986; Laurent and Simons, 2009) and is also associated with impaired quality of life (Mogotsi et al., 2000). However, after implementing the two-step Heckman model, benzodiazepine use was no longer associated with loss of libido. This may be due to the differences between the two groups of respondents: PWID who completed the questionnaire in a face-to-face interview attended low-threshold centers and had more socioeconomic and mental difficulties than those who completed it online. The latter group were probably more likely to have stable housing, employment, etc. Mixing benzodiazepines and opioids can lead to poorer outcomes in social functioning, physical and mental health, risk practices and criminal activity (Lintzeris and Nielsen, 2010). 
Participants who answered the questionnaire online were more likely to report loss of libido than those who answered it in face-to-face interviews. This may be because face-to-face interviewing tends to lead to stronger desirability bias (defined by Crowne and Marlowe, 1960 as seeking approval by responding, consciously or unconsciously, in a more socially desirable manner) than would occur with a computer. Questions about sexuality are sensitive and can be interpreted as an invasion of privacy, leading to distorted responses (Tourangeau and Smith, 1996). In addition, the effect of gender relations, specifically domination, still determines our sexualities because of associated social representations (El-Bassel et al., 2003; Rosen and Althof, 2008; Teoh et al., 2017; Xia et al., 2013). To counter the possibility of social desirability bias arising from responses conforming to social norms, computer-assisted self-administrated interviewing provides a greater sense of privacy than face-to-face interviews (Newman et al., 2002).

Some study limitations have to be acknowledged. The relationship between opioids and sexuality is not only a question of biological and pharmacological factors, but involves a complex interaction between context, psychology and society. For example, being in a stable partnership or having various sex partners may be important in terms of libido. No information was collected about marital status or sexual life because it was not necessary for the primary objective of the main PrebupIV study. Two studies, surveying 204 opioid users (Quaglio et al., 2008) and 150 opioid users' spouses (Noori et al., 2008), respectively, found that opioid users living with a partner had a greater libido than single people, but that the partner's history of drug consumption was determinant: disorders related to libido were more frequent in users whose partners had a history of consumption or had started to consume.

A second limitation is the term "loss of libido" which may mean different things to different people. Future studies may allow us to better understand the different dimensions of loss of libido by using the IIEF scale (International Index of Erectile Function using 5 or 15 
questionnaire items), which explores satisfaction, orgasm, erection and sexual desire. Since the PrebupIV questionnaire was developed primarily to determine the acceptability of injectable buprenorphine as a novel OST, loss of libido was not a priority topic, so this section of the questionnaire was not particularly developed. Accordingly, semiotics (the meaning of each word inducing an individual interpretation), may have not been adequately examined when generating the questionnaire items and may have led to bias in the answers. Age is also a factor influencing sexuality because it has an impact on erectile function (Nik Jaafar et al., 2013; Yee et al., 2016) but not necessarily on desire. Accordingly, "loss of libido" does not necessarily mean sexual dysfunction, rather a loss of desire, so age was logically not correlated to this variable.

\subsection{Conclusion}

Loss of libido is a known but under-researched side effect of OST. PWID rarely discuss their sexuality with peers, health professionals or field workers, as it is a sensitive and very private issue for all concerned. However, discussion about sexuality and loss of libido should be initiated at the very beginning of OST prescription. Although this side effect is often forgotten and not taken into account to determine the best OST, it may be of key importance to improve treatment adherence and efficacy. Libido can also be another argument for treatment initiation. The type of opioid consumed plays a significant role in how serious the loss of libido is, and this fact should be taken into account at treatment initiation: in our study, injecting heroin, sulfate morphine and methadone had a strong effect on loss of libido, while buprenorphine appeared to be the OST with the weakest effect. Adequate treatment with a patient-tailored dosing schedule is a key element to improving quality of life (Connock et al., 2007; Maremmani et al., 2007). Other strategies can be chosen if the OST cannot be changed. For example, the time of day at which the dose is taken may have an influence. More specifically, when an OST 
has just been taken, its pharmacological power is high so it is unlikely that libido is strong. When its effects reduce, libido and sexual function in general increase for some users. Alternative medicine can be helpful to improve some sexual functions. A recent double-blind, randomized, and placebo-controlled clinical trial showed that Rosa Damascena oil helped decrease sexual dysfunction and increase testosterone levels in methadone patients (Farnia et al., 2017).

Further studies on the effects of OST on libido are necessary: for example, the dose-response relationship produced by methadone or buprenorphine on sexual functions are still unknown, and studies on women are scarce (Giacomuzzi et al., 2009; Grover et al., 2014). The effects and mechanisms of morphine sulfate on sexuality of PWID represents virgin territory for research. 


\section{Conflict of interest}

No conflict declared.

\section{Role of funding sources}

Funding for this study was provided by the French Inter-ministerial Mission for Combating Drugs and Addictive Behaviors (MILDECA). The MILDECA had no role in the study design, collection, analysis or interpretation of the data, in the writing of the manuscript, or the decision to submit the paper for publication.

\section{Contributors}

PR, PC, SM, MM, VL and DRC designed the study and wrote the protocol. KN and CP conducted the statistical analysis. LBM and PR wrote the first draft of the manuscript and PC, $\mathrm{CP}$ and $\mathrm{OF}$ contributed to critical revision. All authors contributed to and have approved the final manuscript.

\section{Acknowledgments}

We thank all members of the PrebupIV Study Group and all the stakeholders involved, especially participating centers, their staff, and in particular the study participants. Our thanks also to Jude Sweeney for the English revision and editing of our manuscript.

The PrebupIV Study Group: P.Carrieri, P.Chappard, E.Choucair, M.Debrus, R. Delacroix, M.Dematteis, V.Doré, N. Joannard, V.Laporte, M.Mora, A.Morel, S.Morel, K.Ndiaye, 
F.Olivet, E.Pletschinger, D.Rojas-Castro, P.Roux, B.Spire, M.Suzan, G.Maradan, F. Vorspan.

Participating centers and their staff: S.Longere (Marseille (Bus 31/32)); J.Levy (Marseille

(Nouvelle Aube)) ; ASUD (Marseille) ; M.Debrus (Paris (Gaïa)) ; CAARUD AIDES :

G.Penavayre (Pau), C.Labbe (Lille), R.Delacroix (Paris 02), T.Salaun (Rouen/Le Havre),

S.Ngiema (Le Havre), D.Abouhari (Chartres), S.Le Friec (Brest), F.Crossouard (Rennes),

V.Meignan (Laval), A.Celdran (La Roche-sur-Yon), J.Kubath (Bayonne), N.Fleuranceau-

Rodier (Limoges), L.Baptiste (Niort), Y.Charrier (Angoulême), J.Lamant (La Rochelle),

S.Coulmain (Poitiers), G.Collin (Clermont-Ferrand), C.De Froment (Toulouse),

S.MC.Cormack (Béziers), C.Urdiales (Nîmes), T.Pivi (Nancy), A.Herter (Metz), JL.Ferry

(Thionville), M.Daoud (Epinal), E.Bauer (Besançon), P.Skamba (Mulhouse), R.Taugourdeau

(Nevers), L.Bernard (Avignon), LA.Parent (Toulon), E-Y.Lemonnier (Grenoble), E.Marty

(Bourg en Bresse).

\section{References}

Al-Gommer, O., George, S., Haque, S., Moselhy, H., Saravanappa, T., 2007. Sexual Dysfunctions in Male Opiate Users: A Comparative Study of Heroin, Methadone, and Buprenorphine. Addict. Disord. Their Treat. 6, 137-143.

Babakhanian, M., Alam Mehrjerdi, Z., Shenaiy, Y., 2012. Sexual dysfunction in male crystalline heroin dependents before and after MMT: a pilot study. Arch. Iran. Med. 15, 751-755. https://doi.org/0121512/AIM.006

Barlow, D.H., 1986. Causes of sexual dysfunction: The role of anxiety and cognitive interference. J. Consult. Clin. Psychol., Special Series: Current Issues in the Evaluation and Treatment of Sexual Disturbance 54, 140-148. https://doi.org/10.1037/0022-006X.54.2.140

Bliesener, N., Albrecht, S., Schwager, A., Weckbecker, K., Lichtermann, D., Klingmüller, D., 2005. Plasma Testosterone and Sexual Function in Men Receiving Buprenorphine Maintenance for Opioid Dependence. J. Clin. Endocrinol. Metab. 90, 203-206. https://doi.org/10.1210/jc.2004-0929 
Blom Nilsson, M., Chassler, D., Lundgren, L.M., 2015. Factors associated with work and taking prescribed methadone or buprenorphine among Swedish opiate addicts. Eval. Program Plann. 49, 172-177. https://doi.org/10.1016/j.evalprogplan.2014.12.015

Brisacier, A.-C., 2017. Tableau de bord annuel des traitements de substitution aux opiacés 2017.

Budtz-Jørgensen, E., Keiding, N., Grandjean, P., Weihe, P., 2007. Confounder Selection in Environmental Epidemiology: Assessment of Health Effects of Prenatal Mercury Exposure. Ann. Epidemiol. 17, 27-35. https://doi.org/10.1016/j.annepidem.2006.05.007

Cadet-Taïrou, A., Saïd, S., Martinez, M., 2015. Profils et pratiques des usagers des CAARUD en 2012. Tendances, OFDT.

Carrieri, P.M., Michel, L., Lions, C., Cohen, J., Vray, M., Mora, M., Marcellin, F., Spire, B., Morel, A., Roux, P., Group, the M.S., 2014. Methadone Induction in Primary Care for Opioid Dependence: A Pragmatic Randomized Trial (ANRS Methaville). PLOS ONE 9, e112328. https://doi.org/10.1371/journal.pone.0112328

Chekuri, V., Gerber, D., Brodie, A., Krishnadas, R., 2012. Premature ejaculation and other sexual dysfunctions in opiate dependent men receiving methadone substitution treatment. Addict. Behav. 37, 124-126. https://doi.org/10.1016/j.addbeh.2011.08.005

Cicero, T.J., Bell, R.D., Wiest, W.G., Allison, J.H., Polakoski, K., Robins, E., 1975. Function of the Male Sex Organs in Heroin and Methadone Users. N. Engl. J. Med. 292, 882-887. https://doi.org/10.1056/NEJM197504242921703

Connock, M., Juarez-Garcia, A., Jowett, S., Frew, E., Liu, Z., Taylor, R.J., Fry-Smith, A., Day, E., Lintzeris, N., Roberts, T., Burls, A., Taylor, R.S., 2007. Methadone and buprenorphine for the management of opioid dependence: a systematic review and economic evaluation. Health Technol. Assess. Winch. Engl. 11, 1-171, iii-iv.

Crowne, D.P., Marlowe, D., 1960. A new scale of social desirability independent of psychopathology. J. Consult. Psychol. 24, 349-354. https://doi.org/10.1037/h0047358

Dunn, K.M., Croft, P.R., Hackett, G.I., 1999. Association of sexual problems with social, psychological, and physical problems in men and women: a cross sectional population survey. J. Epidemiol. Community Health 53, 144-148.

El-Bassel, N., Gilbert, L., Rajah, V., 2003. The relationship between drug abuse and sexual performance among women on methadone: Heightening the risk of sexual intimate violence and HIV. Addict. Behav. 28, 1385-1403. https://doi.org/10.1016/S0306-4603(02)00266-6

Emmanuelli, J., Desenclos, J.-C., 2005. Harm reduction interventions, behaviours and associated health outcomes in France, 1996-2003. Addiction 100, 1690-1700. https://doi.org/10.1111/j.1360-0443.2005.01271.x

Farnia, V., Tatari, F., Alikhani, M., Shakeri, J., Taghizadeh, M., Karbasizadeh, H., Sadeghi Bahmani, D., Holsboer-Trachsler, E., Brand, S., 2017. Rosa Damascena oil improved sexual function and testosterone in male patients with opium use disorder under methadone maintenance therapy-results from a double-blind, randomized, placebo-controlled clinical trial. Drug Alcohol Depend. 176, 117-125. https://doi.org/10.1016/j.drugalcdep.2017.02.008

Gerra, G., Manfredini, M., Somaini, L., Maremmani, I., Leonardi, C., Donnini, C., 2015. Sexual Dysfunction in Men Receiving Methadone Maintenance Treatment: Clinical History and Psychobiological Correlates. Eur. Addict. Res. 22, 163-175. https://doi.org/10.1159/000441470

Giacomuzzi, S.M., Khreis, A., Riemer, Y., Garber, K., Ertl, M., 2009. Buprenorphine and Methadone Maintenance Treatment - Sexual Behaviour and Dysfunction Prevalence. Lett. Drug Des. Discov. 6, 13-13. https://doi.org/10.2174/157018009787158580

Grover, S., Mattoo, S.K., Pendharkar, S., Kandappan, V., 2014. Sexual Dysfunction in Patients with Alcohol and Opioid Dependence. Indian J. Psychol. Med. 36, 355-365. https://doi.org/10.4103/0253-7176.140699

Gulliford, S.M., 1998. Opioid-Induced Sexual Dysfunction. J. Pharm. Care Pain Symptom Control 6, 67-74. https://doi.org/10.1300/J088v06n02_05 
Hallinan, R., Byrne, A., Agho, K., McMahon, C.G., Tynan, P., Attia, J., 2009. Hypogonadism in men receiving methadone and buprenorphine maintenance treatment. Int. J. Androl. 32, 131139. https://doi.org/10.1111/j.1365-2605.2007.00824.x

Hernández, M., Alfonso, C.A., 1997. Psychoactive Drugs and Sexuality. Int. J. Ment. Health 26, 68-78. https://doi.org/10.1080/00207411.1997.11449388

Hubbard, R.L., Craddock, S.G., Anderson, J., 2003. Overview of 5-year followup outcomes in the drug abuse treatment outcome studies (DATOS). J. Subst. Abuse Treat. 25, 125-134.

La Torre, A., Giupponi, G., Duffy, D.M., Pompili, M., Grözinger, M., Kapfhammer, H.P., Conca, A., 2014. Sexual dysfunction related to psychotropic drugs: a critical review. Part III: $\mathrm{mood}$ stabilizers and anxiolytic drugs. Pharmacopsychiatry 47, 1-6. https://doi.org/10.1055/s-00331358683

Laurent, S.M., Simons, A.D., 2009. Sexual dysfunction in depression and anxiety: Conceptualizing sexual dysfunction as part of an internalizing dimension. Clin. Psychol. Rev. 29, 573-585. https://doi.org/10.1016/j.cpr.2009.06.007

Lawrinson, P., Ali, R., Buavirat, A., Chiamwongpaet, S., Dvoryak, S., Habrat, B., Jie, S., Mardiati, R., Mokri, A., Moskalewicz, J., Newcombe, D., Poznyak, V., Subata, E., Uchtenhagen, A., Utami, D.S., Vial, R., Zhao, C., 2008. Key findings from the WHO collaborative study on substitution therapy for opioid dependence and HIV/AIDS. Addiction 103, 1484-1492.

Lintzeris, N., Nielsen, S., 2010. Benzodiazepines, Methadone and Buprenorphine: Interactions and Clinical Management. Am. J. Addict. 19, 59-72. https://doi.org/10.1111/j.15210391.2009.00007.x

Maremmani, I., Pani, P.P., Pacini, M., Perugi, G., 2007. Substance use and quality of life over 12 months among buprenorphine maintenance-treated and methadone maintenance-treated heroin-addicted patients. J. Subst. Abuse Treat. 33, 91-98. https://doi.org/10.1016/j.jsat.2006.11.009

Mendelson, J.H., Mello, N.K., 1975. Plasma testosterone levels during chronic heroin use and protracted astinence. A study of Hong Kong addicts. Clin. Pharmacol. Ther. 17, 529-533.

Mintz, J., O'Hare, K., O'Brien, C.P., Goldschmid, J., 1974. Sexual Problems of Heroin Addicts. Arch. Gen. Psychiatry 31, 700-703. https://doi.org/10.1001/archpsyc.1974.01760170088014

Mogotsi, M., Kaminer, D., Stein, D.J., 2000. Quality of Life in the Anxiety Disorders. Harv. Rev. Psychiatry 8, 273-282. https://doi.org/10.1080/hrp.8.6.273

Newman, J.C., Des Jarlais, D.C., Turner, C.F., Gribble, J., Cooley, P., Paone, D., 2002. The Differential Effects of Face-to-Face and Computer Interview Modes. Am. J. Public Health 92, 294-297.

Nik Jaafar, N.R., Mislan, N., Abdul Aziz, S., Baharudin, A., Ibrahim, N., Midin, M., Das, S., Sidi, H., 2013. Risk Factors of Erectile Dysfunction in Patients Receiving Methadone Maintenance Therapy. J. Sex. Med. 10, 2069-2076. https://doi.org/10.1111/jsm.12105

Noori, R., Rafiey, H., Solaimani-nia, L., Narenjiha, H., Assari, S., Lankarani, M.M., 2008. Impact of Spouse's Opiate Dependence on the Partner's. J. Fam. Reprod. Health 2, 185-180.

Peyriere, H., Nogue, E., Eiden, C., Frauger, E., Charra, M., Picot, M.-C., List of investigators, 2016. Evidence of slow-release morphine sulfate abuse and diversion: epidemiological approaches in a French administrative area. Fundam. Clin. Pharmacol. 30, 466-475. https://doi.org/10.1111/fcp.12210

Quaglio, G., Lugoboni, F., Pattaro, C., Melara, B., Mezzelani, P., Des Jarlais, D.C., 2008. Erectile dysfunction in male heroin users, receiving methadone and buprenorphine maintenance treatment. Drug Alcohol Depend. 94, 12-18. https://doi.org/10.1016/j.drugalcdep.2007.09.025

Rosen, R.C., Althof, S., 2008. Impact of Premature Ejaculation: The Psychological, Quality of Life, and Sexual Relationship Consequences. J. Sex. Med. 5, 1296-1307. https://doi.org/10.1111/j.1743-6109.2008.00825.x

Roux, P., Carrieri, M.P., Cohen, J., Ravaux, I., Poizot-Martin, I., Dellamonica, P., Spire, B., 2009. Retention in Opioid Substitution Treatment: A Major Predictor of Long-Term Virological 
Success for HIV-Infected Injection Drug Users Receiving Antiretroviral Treatment. Clin. Infect. Dis. 49, 1433-1440. https://doi.org/10.1086/630209

Roux, P., Rojas Castro, D., Ndiaye, K., Briand Madrid, L., Laporte, V., Mora, M., Maradan, G., Morel, S., Spire, B., Carrieri, P., 2017. Willingness to receive intravenous buprenorphine treatment in opioid-dependent people refractory to oral opioid maintenance treatment: results from a community-based survey in France. Subst. Abuse Treat. Prev. Policy 12, 46. https://doi.org/10.1186/s13011-017-0131-4

Santen, F.J., Sofsky, J., Bilic, N., Lippert, R., 1975. Mechanism of action of narcotics in the production of menstrual dysfunction in women. Fertil. Steril. 26, 538-548.

Teoh, J.B.F., Yee, A., Danaee, M., Ng, C.G., Sulaiman, A.H.B., 2017. Erectile Dysfunction Among Patients on Methadone Maintenance Therapy and Its Association With Quality of Life. J. Addict. Med. 11, 40-46. https://doi.org/10.1097/ADM.0000000000000267

Tourangeau, R., Smith, T.W., 1996. Asking sensitive questions: The impact of data collection mode, question format, and question context. Public Opin. Q. 60, 275-304.

Xia, Y., Zhang, D., Li, Xiaoming, Chen, W., He, Q., Jahn, H.J., Li, Xin, Chen, J., Hu, P., Ling, L., 2013. Sexual dysfunction during methadone maintenance treatment and its influence on patient's life and treatment: a qualitative study in South China. Psychol. Health Med. 18, 321-329. https://doi.org/10.1080/13548506.2012.729845

Yee, A., Danaee, M., Loh, H.S., Sulaiman, A.H., Ng, C.G., 2016. Sexual Dysfunction in Heroin Dependents: A Comparison between Methadone and Buprenorphine Maintenance Treatment. PLoS ONE 11. https://doi.org/10.1371/journal.pone.0147852

Yee, A., Loh, H.S., Hisham Hashim, H.M.B., Ng, C.G., 2014. Clinical factors associated with sexual dysfunction among men in methadone maintenance treatment and buprenorphine maintenance treatment: a meta-analysis study. Int. J. Impot. Res. 26, 161-166. https://doi.org/10.1038/ijir.2014.18

Zhang, Minying, Zhang, H., Shi, C.X., McGoogan, J.M., Zhang, B., Zhao, L., Zhang, Mianzhi, Rou, K., Wu, Z., 2014. Sexual Dysfunction Improved in Heroin-Dependent Men after Methadone Maintenance Treatment in Tianjin, China. PLoS ONE 9. https://doi.org/10.1371/journal.pone.0088289 
Table 1. Sociodemographic and behavioral characteristics of people who inject opioids, the prebupIV survey $(\mathrm{n}=514$ participants $)$

\begin{tabular}{|c|c|c|c|c|}
\hline & $\begin{array}{c}\text { Survey on } \\
\text { paper } \\
375(73 \%)\end{array}$ & $\begin{array}{c}\text { Survey online } \\
139(27 \%)\end{array}$ & & $\begin{array}{c}\text { Total } \\
514\end{array}$ \\
\hline & $\mathbf{N}(\%)$ & $\mathbf{N}(\%)$ & p-value & $\mathbf{N}(\%)$ \\
\hline Gender & & & 0.010 & \\
\hline male & $309(83)$ & $99(73)$ & & $408(80)$ \\
\hline female & $63(17)$ & $37(27)$ & & $100(20)$ \\
\hline \multicolumn{5}{|l|}{ Age - years $^{\S 1}$} \\
\hline Median [IQR] & $34[30 ; 41]$ & $30[24 ; 42]$ & 0.002 & $34[28 ; 41]$ \\
\hline Stable housing & & & 0.079 & \\
\hline No & $173(46)$ & $52(38)$ & & $225(44)$ \\
\hline Yes & $200(54)$ & $86(62)$ & & $286(56)$ \\
\hline Employment $^{1}$ & & & $<0.001$ & \\
\hline No & $280(76)$ & $76(58)$ & & $356(71)$ \\
\hline Yes & $90(24)$ & $54(42)$ & & $144(29)$ \\
\hline Opioids consumed most ${ }^{* 1}$ & & & $<0.001$ & \\
\hline Buprenorphine & $181(58)$ & $61(44)$ & & $242(54)$ \\
\hline Heroin & $47(15)$ & $42(30)$ & & $89(20)$ \\
\hline Morphine sulfate & $57(18)$ & $21(15)$ & & $78(17)$ \\
\hline Methadone & $25(8)$ & $4(3)$ & & $29(6)$ \\
\hline other opioids ${ }^{\&}$ & $4(1)$ & $10(7)$ & & $14(3)$ \\
\hline \multicolumn{5}{|l|}{ Frequency of injection - days } \\
\hline Median [IQR] & $30[15 ; 30]$ & $30[13 ; 30]$ & 0.781 & $30[15 ; 30]$ \\
\hline \multicolumn{5}{|l|}{ Injection duration - years } \\
\hline Median [IQR] & $8[4 ; 13]$ & $5[2 ; 9]$ & 0.004 & $7[3 ; 11]$ \\
\hline Stimulant use ${ }^{* \# 1}$ & & & $<0.001$ & \\
\hline No & $122(33)$ & $86(63)$ & & $208(41)$ \\
\hline Yes & $250(67)$ & $50(37)$ & & $300(59)$ \\
\hline Benzodiazepine use ${ }^{*}$ & & & 0.825 & \\
\hline No & $245(66)$ & $91(67)$ & & $336(66)$ \\
\hline Yes & $127(34)$ & $45(33)$ & & $172(34)$ \\
\hline Alcohol consumption*1 & & & $<0.001$ & \\
\hline No & $190(51)$ & $101(73)$ & & $291(57)$ \\
\hline Yes & $185(49)$ & $38(27)$ & & $223(43)$ \\
\hline Currently on OST & & & 0.982 & \\
\hline No & $111(30)$ & $41(30)$ & & $152(30)$ \\
\hline Yes & $264(70)$ & $98(70)$ & & $362(70)$ \\
\hline
\end{tabular}

$\S$ Min $=18 ; \operatorname{Max}=62 ;$ Mean $=34.9$

$*$ during the previous 12 months

$\mathrm{IQR}=$ Interquartile range

OST $=$ Opioid Substituion Treatment

\& Oxycodone (6), codeine (6), fentanyl (1) or tramadol (1)

\# Cocaine, Crack, free base, speedball, amphetamines or methylphenidate

${ }^{1}$ variable used in the model to calculate IMR 
Table 2. Factors independently associated with loss of libido in the prebupIV population; univariate analyses with OR (coefficient) estimates based on logistic regression (Heckman model) analyses, $\mathrm{n}=514$ participants.

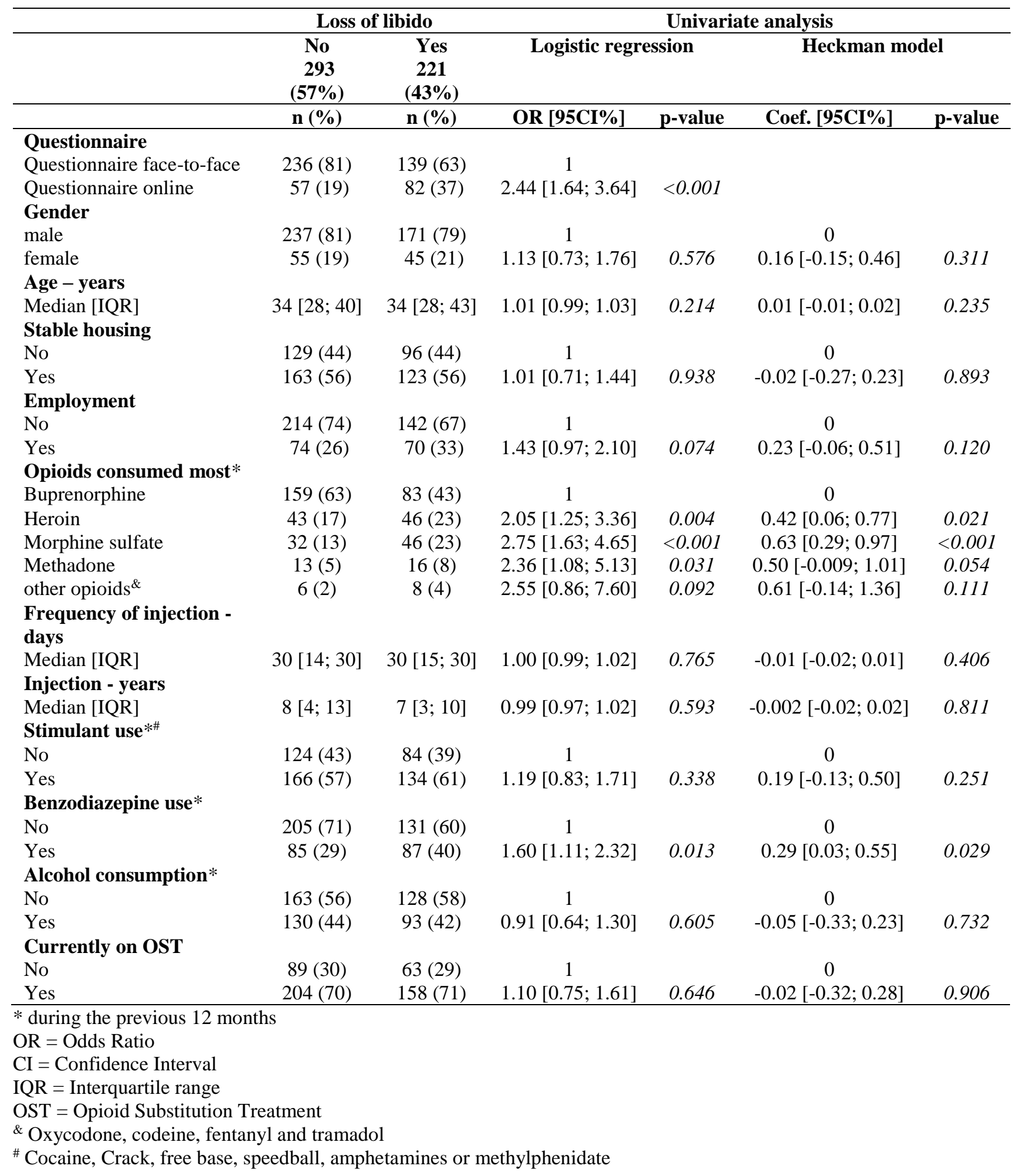


Table 3. Factors independently associated with loss of libido in the prebupIV population; multivariable analyses with OR (coefficient) estimates based on logistic regression (Heckman model) analyses.

\begin{tabular}{|c|c|c|c|c|c|c|}
\hline & \multicolumn{2}{|c|}{ Loss of libido } & \multicolumn{4}{|c|}{ Multivariable analysis } \\
\hline & \multirow{2}{*}{$\begin{array}{c}\text { No } \\
(57 \%)\end{array}$} & \multirow{2}{*}{$\begin{array}{c}\text { Yes } \\
(43 \%) \\
n(\%)\end{array}$} & \multicolumn{2}{|c|}{$\begin{array}{l}\text { Logistic regression } \\
(\mathrm{n}=446 \text { participants) }\end{array}$} & \multicolumn{2}{|c|}{$\begin{array}{c}\text { Heckman model } \\
(\mathrm{n}=436 \text { participants })\end{array}$} \\
\hline & & & OR [95CI\%] & p-value & Coef. $[95$ CI\%] & p-value \\
\hline \multicolumn{7}{|l|}{ Questionnaire } \\
\hline Questionnaire face-to-face & $195(80)$ & $116(62)$ & 1 & & 0 & \\
\hline Questionnaire online & $48(20)$ & $70(38)$ & $2.55[1.64 ; 3.96]$ & $<0.001$ & $-0.10[-0.80 ; 0.61]$ & 0.788 \\
\hline \multicolumn{7}{|l|}{ Opioids consumed most $*$} \\
\hline Buprenorphine & $159(63)$ & $83(43)$ & 1 & & 0 & \\
\hline Heroin & $43(17)$ & $46(23)$ & $1.55[0.92 ; 2.61]$ & 0.096 & $0.42[0.07 ; 0.76]$ & 0.019 \\
\hline Morphine sulfate & $32(13)$ & $46(23)$ & $2.67[1.56 ; 4.58]$ & $<0.001$ & $0.63[0.30 ; 0.97]$ & $<0.001$ \\
\hline Methadone & $13(5)$ & $16(8)$ & $2.50[1.13 ; 5.56]$ & 0.030 & $0.50[0.02 ; 0.98]$ & 0.031 \\
\hline other opioids $^{\&}$ & $6(2)$ & $8(4)$ & $1.54[0.49 ; 4.83]$ & 0.456 & $0.61[-0.25 ; 1.48]$ & 0.169 \\
\hline \multicolumn{7}{|l|}{ Benzodiazepine use ${ }^{*}$} \\
\hline No & $170(70)$ & $110(59)$ & 1 & & & \\
\hline Yes & $73(30)$ & $76(41)$ & $1.62[1.07 ; 2.44]$ & 0.022 & & \\
\hline IMR & & & & & $0.45[0.001 ; 0.91]$ & 0.049 \\
\hline
\end{tabular}

* during the previous 12 months

$\mathrm{OR}=$ Odds Ratio

$\mathrm{CI}=$ Confidence Interval

\& Oxycodone, codeine, fentanyl and tramadol 